\title{
ENTRE RAÍZES AÉREAS E EXOESQUELETOS: A PRODUÇÃO DE CURRÍCULOS DE BIOLOGIA
}

\author{
SANDRA NAZARÉ DIAS BASTOS \\ Universidade Federal do Pará \\ SÍLVIA NOGUEIRA CHAVES \\ Universidade Federal do Pará
}

RESUMO Este trabalho visa discutir o currículo como construção histórica, produto de diferentes intencionalidades, jogos de saber-poder e escolhas que inevitavelmente levam a inclusões e exclusões. Nossas análises estão entrelaçadas às ferramentas teóricas para mapear enunciados, pensadas por Michel Foucault, e que, relacionadas a prescrições e determinações, inventam um currículo de Biologia que não só privilegia, mas fomenta a necessidade de "especificidades", como um olhar diferenciado sobre a natureza, procedimentos práticos e experimentais, além de dependências e equipamentos para acontecer de forma aceitável. Ressaltamos, no entanto, que, se por um lado é possivel entender o currículo como esse conjunto de ordenamentos e de linhas fixas, por outro lado, é possivel (e também desejável!) ver e exercitar possibilidades de rompimento que nos levem a ter disponibilidade para que outras sensibilidades e (bio) lógicas nos habitem. Quem sabe assim, um dia, a Biologia possa ser também poesia e voltar a ter vida na sala de aula.

Palavras-chave: Currículo. Educação Científica. Ensino de Ciências.

\section{ABSTRACT ABOUT AERIAL ROOTS AND EXOSKELETONS: THE PRODUCTION OF BIOLOGY CURRICULUMS}

This work aims to discuss the curriculum as a historical construction, product of different intentionalities, games of power-knowledge and choices that inevitably lead to inclusions and exclusions. Our analyzes are intertwined with the theoretical tools thought by Michel Foucault to map statements that, related to prescriptions and determinations, invent a curriculum of Biology that not only privileges but fosters the need for "specificities" as a different look at nature, practical and experimental procedures, as well as dependencies and equipment to happen in an acceptable manner. We emphasize, however, that if, in one hand, it is possible to understand the curriculum 
as such a set of ordinances and fixed lines, on the other hand, it is possible (and also desirable!) to see and exercise possibilities of disruption that lead us to be available for other sensibilities and (Bio) logics to inhabit us. Who knows, one day, biology can also be poetry and come back to life in the classroom.

Keywords: Curriculum. Scientific Education. Science Teaching.

\section{RESUMEN ENTRE RAÍCES AÉREAS Y EXOESQUELETOS: LA PRODUCCIÓN DE CURRÍCULOS DE BIOLOGÍA}

Este trabajo muestra discutir el currículo como construcción histórica, producto de diferentes intenciones, juegos de saber-poder y elecciones que inevitablemente llevan a las inclusiones y exclusiones. Nuestros análisis están entrelazados a las herramientas teóricas pensadas por Michel Foucault para mapear enunciados que, relacionadas a prescripciones, determinaciones, inventan un currículo de Biología que no sólo distingue, sino también fomenta la necesidad de "especificidades" como una mirada diferenciada sobre la naturaleza, procedimientos prácticos y experimentales, además de dependencias y equipamientos para ocurrir de forma aceptable. Resaltamos, no obstante, que, si por un lado es posible entender el currículo como ese conjunto de ordenamientos y de líneas fijas, por otro lado, es posible (y jtambién deseable!) ver y ejercitar las posibilidades de rompimientos que nos lleven a tener disponibilidad para que otras sensibilidades y (Bio) lógicas nos habiten. Quien sabe así, un día, la biología pueda ser también poesía y vuelva a haber vida en la sala de clase.

Palabras claves: Currículo. Educación Científica. Enseñanza de Ciencias.

\section{Prólogo}

Um ordenamento de matérias, conceitos, conhecimentos. Uma trajetória a ser cumprida. Um caminho. Assim é o currículo! De tão fechado e linear parece que já nasceu assim: pronto, acabado, imexivel (como diria certa figura pública). No entanto, o currículo e seus componentes constituem um conjunto articulado e normatizado de saberes regidos por determinada ordem, que, por sua vez, é estabelecida em arenas de lutas que incluem visões de mundo e a produção de significados sobre as coisas e os seres do mundo (COSTA, 2005).
Partindo do pressuposto de que o currículo é invenção, entendemos que as várias formas que assume são construídas na história e obedecem a diferentes discursividades, o resultado é produto de diferentes intencionalidades, jogos de saber-poder, escolhas que inevitavelmente levam a inclusões e exclusões. Dessa forma, o currículo não é neutro, uma vez que ao selecionar conteúdos, privilegiar um tipo de conhecimento, destacar, entre múltiplas possibilidades, uma identidade ou subjetividade como sendo a ideal, envolve relações de saber poder que 
o localizam em um território contestado (SILVA, 2010). Assim, como prática social discursiva e não discursiva, o currículo materializa-se em instituições, saberes, normas, programas, prescrições e modos de ser sujeito (CORAZZA, 2001).

É sobre essa ideia que vamos construindo esse texto. É importante ressaltar que, se por um lado, é possivel entender o currículo como esse conjunto de ordenamentos e de linhas fixas, por outro lado, é possivel (e também desejável!) ver e exercitar possibilidades de rompimento, como afirma Paraíso (2009). Por ser um artefato criado na cultura, o currículo permite possibilidades de diálogo com a vida e, nesse contexto, é um artefato com um mundo a explorar.

\section{Memórias}

Não vale à pena se preocupar, está tudo misturado. Uma coisa se dissolve na outra. A memória não é objetiva, ela inventa, seleciona, elimina, burila, lixa, tira o supérfluo, semeia, cria o que lhe apetece. Pelo menos a dos artistas. É uma versão, não tem compromisso com os fatos [...].

Lygia Fagundes Telles (2009, p. 131)

A professora havia falado quão maravilhosos eram os vegetais e a menina saiu da aula empolgada tentando identificar nas plantas do caminho até sua casa todas aquelas estruturas ensinadas pela professora. Mangueira tem raiz, caule (grosso e marrom igual ao do desenho), folhas, frutos, flores. Opa! Não vejo as flores, na verdade, não me lembro de ter visto flores em uma mangueira. Como elas seriam? Existiriam mesmo? A mangueira deve ser um vegetal incompleto. Vagueando em seus pensamentos estava a lembrança do novo conceito explicado pela professora. Vamos tentar com o açaizeiro: Raízes, ok. Caule (um pouco mais fino e menos marrom), ok. Folhas, ok. Frutos, ok... mas, também um vegetal sem flores. Outro vegetal incompleto, pensou. Outra aula de ciências e mais coisas sobre Botânica foram ensinadas. Dessa vez, a professora deteve-se na raiz, a parte que servia para a fixação das plantas e para a retirada dos nutrientes do solo. Ela teve a impressão de que havia entendido tudinho o que a professora explicara e com isso, ficou muito feliz. As raízes aquáticas são aquelas raízes que retiram nutrientes da água; as raízes terrestres são aquelas que fixam o vegetal no solo e dali tiram os nutrientes; as raízes aéreas ficavam acima do solo. Que beleza de aula, pensou a menina, agora era só procurar as plantas no caminho para tentar identificar as raízes que a professora havia falado. 0 mururé devia ter uma raiz aquática. Embora não pudesse vê-la naquele momento, a plantinha estava na água e quando era puxada para fora dava pra ver suas raízes escuras. A mangueira e o açaizeiro estão presos ao solo e dessa forma suas raízes, obviamente, só poderiam ser terrestres. Mas a curiosidade mesmo, aquela que mal podia conter dentro de si, era aquela de ver uma raiz aérea. Como deveria ser interessante observar uma árvore de cabeça para baixo, com suas raízes esvoaçantes retirando seus nutrientes do ar. Era assim que em seu pensamento se desenhava uma fascinante raiz aérea...

Procurou muito por onde andava... Até no sítio enorme do avô, onde passou as férias. Procurou também na beira da estrada, nas margens do igarapé. Nada! Nenhuma raiz aérea apareceu. Embora sua entrada na escola fosse bem recente, possivelmente ela já havia sido contaminada pelo maior problema de nosso tempo que é a de ter perdido a capacidade de fazer perguntas. Não ousou falar de suas dúvidas com a professora ou com qualquer outro adulto. Como nos diz Mia Couto (2011), a escola tão jovem em sua vida, já estava ensinando a menina apenas a dar respostas.

Aquela procura demorou apenas o breve intervalo de tempo de um novo assunto ser levantado pela professora. Deixando aquela his- 
tória de lado, a menina começou a aprender sobre os animais e eles também eram muito interessantes e estavam por toda parte. Segundo a professora, eles eram classificados em invertebrados quando não tinham esqueleto e vertebrados quando apresentavam essa estrutura. A professora até levou a figura de uma caveira para mostrar como os ossos apresentavam formas e tamanhos bem diferentes. Muito fácil, pensou a menina: nós, humanos, somos vertebrados por que temos ossos. E mais uma vez saiu da sala com aquela satisfação que invade as crianças quando elas fazem algo bem feito: havia entendido tudo bem direitinho, pois havia prestado atenção em tudo o que a professora falara. E muitos animais vertebrados e invertebrados cruzaram seu caminho para casa naquele dia.

Mas eis que a professora resolve complicar um pouquinho mais, ao mostrar que o esqueleto dos animais poderia ser de dois tipos bem diferentes: dentro do corpo, ele era chamado de endoesqueleto, e, fora do corpo, era chamado de exoesqueleto. Palavras novas, bonitas, grandes e bem dificeis de serem escritas. Mas o que intrigou mesmo a menina foi essa história do esqueleto ficar fora do corpo. Isso era simplesmente fascinante! No caminho para casa, ela ia cruzando com os animais e pensando: cachorro. Não vejo esqueleto, por que deve estar dentro do corpo, portanto, animal vertebrado com endoesqueleto. Gato também, cavalo também, boi também. Mas e o bicho com exoesqueleto, que aparência teria?

Sua curiosidade foi satisfeita quando ao ler o livro "O lobisomem" o autor dizia que em noites de lua cheia o menino, sétimo filho de uma família com seis irmãs, se transformava em uma forma repugnante. Por mais que ele tentasse fugir, a lua o alcançava e quando isso acontecia ele sentia muita dor e suas entranhas se reviravam. Era como se ele virasse do lado avesso. Se era assim mesmo que aconte- cia a transformação (e naquela época era impossivel duvidar das verdades escritas em um livro, ou faladas por um adulto) o lobisomem era o único animal vertebrado que ela conhecia que tinha exoesqueleto. Naquela cabecinha de sete anos, a verdade científica ainda não havia domesticado os pensamentos mágicos

Figura 1 - Raízes aéreas e exoesqueleto.

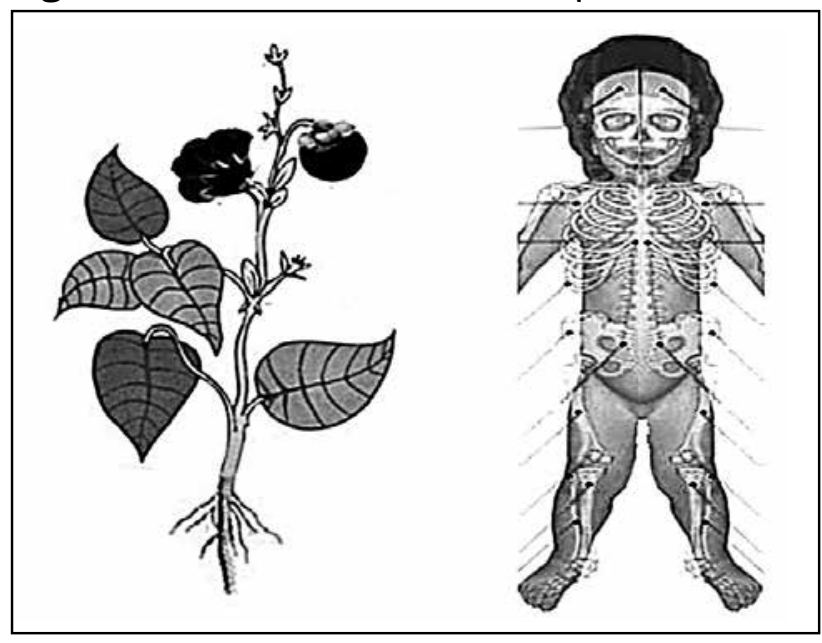

\section{Currículos}

Por ocasião desses episódios, já ia longe o tempo em que os programas das disciplinas científicas estavam voltados para as coisas do dia a dia e pretendiam "ensinar como os sujeitos deveriam lidar com o cotidiano", por meio de um currículo "que incluía a lição de coisas" (WORTMANN, 1999a). Do contrário, a menina saberia facilmente que as raízes aéreas de que falava a professora eram aquelas pontas que saíam da terra, no manguezal, e que ela achava que eram plantas jovens sem galhos ou folhas e que o tão exótico animal com esqueleto fora do corpo bem poderia ser o camarão que ela costumava comer no almoço.

Mas como o ensino de Ciências desapartou-se do cotidiano?

Wortmann explica que inicialmente o conhecimento científico estava disposto na estrutura curricular como mero elemento figurativo, mas começa a ganhar status, especificida- 
des e destaque no currículo escolar, a partir de meados do século XIX, com a implementação de inovações consideradas necessárias para o ensino das Ciências, tais como gabinetes, equipamentos, vidrarias, reagentes, espécimes animais e vegetais (WORTMANN, 1999a).

É importante destacar que essas supostas especificidades vão sendo incorporadas ao ensino das ciências até se tornarem regras, padrões de verdade passíveis de reprodução, sem que sejam questionadas. A partir de um determinado momento, as disciplinas científicas conquistam um lugar "não contestado" no currículo escolar (WORTMANN, 2005). Tais particularidades funcionam como tecnologias, ou melhor dizendo, funcionam como lentes que permitem ver de uma determinada forma, uma vez que direcionam o olhar para uma maneira específica, e dita científica, de ver o mundo. As tecnologias inseridas na escolarização formam objetos:

[...] guiam e legitimam o que é razoável/não razoável como pensamento [...], ordenam quais objetos do mundo são colocados juntos, quais são diferenciados, ao mesmo tempo em que tornam certas coisas dificeis de serem referidas, ou algumas vezes, impossiveis de serem pensadas. (POPKEWITZ, 2010, p. 193)

O conhecimento científico passa então a requerer essas especificidades, suas tecnologias, os espaços especiais para ser trabalhado, ensinado e aprendido. É sobre isso que trata Ivor Goodson (2010), ao descrever como a disciplina Biologia passa a fazer parte do currículo de Ciências, nas escolas inglesas, em substituição ao currículo baseado nas coisas comuns. Mesmo que apresentasse bons resultados, a proposta curricular inicial foi excluída da escola para dar lugar a outro modelo de ciência, um "tipo mais adequado de educação científica" que não mais se preocupava com as coisas cotidianas. Nas palavras do autor: "uma versão diluída de ciência pura, ciência de laboratório, fora aceita como visão correta de ciência, visão que, em grande parte, persistiu não contestada até os nossos dias" (GOODSON, 2010, p. 26).

Ao final do século XIX, o conhecimento formal e acadêmico substituiu o conhecimento prático e utilitário e as disciplinas científicas, inseridas de forma incipiente no currículo escolar, passam a ter lugar de destaque e são atravessadas por toda uma tecnologia que captura e sequestra professores e alunos em seus discursos de verdade, em meados do século seguinte. 0 professor de Ciências tem, a partir de então, que ministrar aulas práticas porque elas são imprescindíveis ao entendimento das ciências; o laboratório é o espaço físico necessário para que as aulas sejam ministradas. Saídas de campo, experimentos de observação, organização de coleções, são as prescrições que entram na ordem de um discurso a partir do qual professores de ciências passam a interpretar, organizar e realizar suas ações pedagógicas.

São essas inovações que determinam um curso dito renovado, moderno e dinâmico, com aulas pretensamente mais interessantes, capazes de motivar o aluno para o estudo através da resolução de problemas. Um curso no qual a formação predominaria sobre a informação, sob a forma de manuais com descrições precisas. Tais especificidades “buscavam se constituir em 'motivos' para convencer os professores a adotarem um 'ensino renovado' e a abandonarem o 'ensino tradicional', pois ressaltavam todas as 'vantagens' educativas implicadas no primeiro" (WORTMANN, 2005, p. 145).

Essa tecnologia discursiva é colocada em operação em meados do século XX, tendo como gatilho o lançamento do satélite artificial Sputnik na atmosfera terrestre. Chassot (2004) relata em detalhes o que esse marco na corrida espacial provocou nos currículos de ciências dos Estados Unidos e países aliados. Pro- 
jetos concebidos por cientistas laureados com o prêmio Nobel e financiados pelos Estados Unidos foram implantados nas escolas da educação básica, com o objetivo de "desenvolver políticas científicas no país e patrocinar pesquisas básicas na educação em ciências". Tudo isso para "promover o progresso da ciência, o avanço da saúde nacional, a prosperidade, o bem-estar e a segurança da defesa nacional" (CHASSOT, 2004, p. 25). Esse acontecimento promove a emergência de um marco histórico que redireciona os rumos daquilo que se pensava (e daquilo que se praticava) no âmbito da educação científica.

Mas por que laureados pelo Nobel e não professores de Ciências são chamados a falar e a determinar os rumos da educação em Ciências a partir de então?

Para Foucault (2009), todo discurso é a reverberação de uma verdade, uma verdade que irrompe, não por ser mais verdadeira, mas porque encontrou as condições possíveis para ser vista como tal. Em outras palavras, tudo aquilo que é dito instaura uma realidade discursiva que se impõe por meio e um sistema de forças. A emergência de um acontecimento (ou verdade) não acontece por acaso, mas se liga a diversos sistemas de submissão que se produzem em determinados estados de força, fazendo da história um grande jogo no qual entrará na ordem do verdadeiro aquele que se apoderar das regras, que tomar o lugar daqueles que as utilizam, que se disfarçar para pervertê-las, utilizá-las, ao inverso e voltá-las contra aqueles que as tinham imposto; aquele que, se introduzindo no aparelho complexo, o fizer funcionar de um determinado modo, de outro modo (FOUCAULT, 1979, p. 24).

Nesse contexto, como bem observa Foucault (2009), para que um discurso seja aceito e ganhe status de verdade é necessário que seja proferido por quem de direito, conforme ritual requerido, apoiando-se sobre suporte institucional. Sendo assim, quem melhor para determinar os rumos da educação em Ciências que aqueles que conhecem suas entranhas e constituem suas engrenagens? Quem melhor que aqueles que reconhecidamente se dedicam a fazer da ciência o instrumento que garantirá a libertação da humanidade de todos os seus problemas? Quem melhor que aqueles que "fazem" e "vivem" a ciência para determinar o que (e como!) deve ser ensinado aos jovens visando o despertar para a carreira científica?

E são eles, os cientistas, com sua ciência redentora, sempre benéfica, capaz de resolver problemas e ser comprovada por via experimental, que saem do confinamento de seus laboratórios de pesquisa e passam a transitar e, por que não dizer, habitar novos espaços. Eles adentram não só as escolas, mas programas familiares cotidianos através da mídia, por exemplo.

Nas revistas em quadrinhos, o personagem Professor Pardal é apresentado em sua eterna luta contra o mal que não raramente é materializado na figura de outro cientista, o maluco Professor Gavião (Figura 2). Ele é descrito como o inventor mais famoso de Patópolis, é amigo das pessoas e tem bons sentimentos com todo mundo, embora ocasionalmente provoque reações irritadas devido a alguns desastres provocados pelos seus inventos.'

Certa vez, preocupado com seus sobrinhos, ele busca em sua ciência respostas para resolver a tristeza das crianças provocada por um dia de chuva que as impede de brincar no quintal. A solução encontrada é a invenção de brinquedos que garantem diversão permanente: uma pipa que não precisa de vento para voar, um pião que gira incessantemente em qualquer tipo de solo e um taco que sempre acerta a bola jogada pelo lançador. Todos ficam muito felizes, no entanto, ante a ausência de desafios, as crianças logo se desinteressam

1 Wikipédia. Disponível em: <http://pt.wikipedia.org/ wiki/Professor_Pardal [acessado em 08/2014]>. 
dos brinquedos inventados pelo tio. Mesmo que as invenções de Pardal não funcionem da maneira que se espera, são sempre as boas intenções que conduzem o processo criativo desse bom cientista.

Figura 2 - Professor Pardal e Professor Gavião. ${ }^{2}$
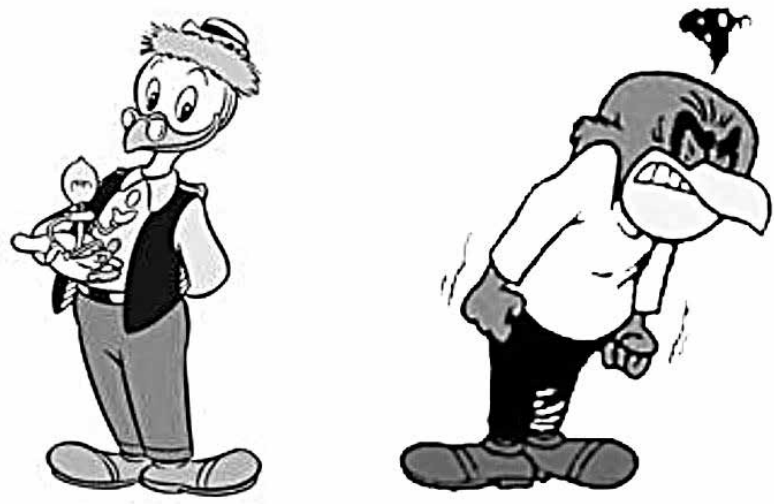

Esse bom cientista não resume suas atividades à esfera doméstica. Ele também é o autor dos apetrechos utilizados pelo atrapalhado herói Morcego Vermelho, no combate às maldades dos temíveis assaltantes Mancha Negra e Irmãos Metralha. Nesse universo em que patos antropomórficos dominam as cenas, a Ciência pode sim cair em mãos erradas e inescrupulosas: as mãos do Professor Gavião, vilão invejoso, mal-humorado e resmungão, que mesmo sendo muito inteligente (pré-requisito básico de todo cientista que se preze), não consegue equiparar-se a Pardal, por isso, vive querendo roubar-lhe os inventos para conseguir riquezas e poder para dominar o mundo. No mundo de Patópolis, no entanto, a ciência pode até ser usada para fazer o mal, mas é o bem que sempre vence.

Nas programações televisivas, os efeitos da ciência não apenas são apresentados como são glamourizados por meio de viagens no tempo e no espaço. Programas da década de 1970, destinados ao público infanto-juvenil como Cosmos, Jeannie é um gênio, Jornada nas Estrelas e Túnel do Tempo (Figura 3), são

2 Disponivel em: <http://blogmaniadegibi.com>. citados por Chaves (2010) como pertencentes a uma eficiente tecnologia capaz de capturar a atenção de jovens e crianças enredando-os em suas tramas discursivas. Tudo isso para forjar uma nova geração de cientistas.

Figura 3 - Programas televisivos: Jeannie e um Gênio, Túnel do Tempo e Cosmos.

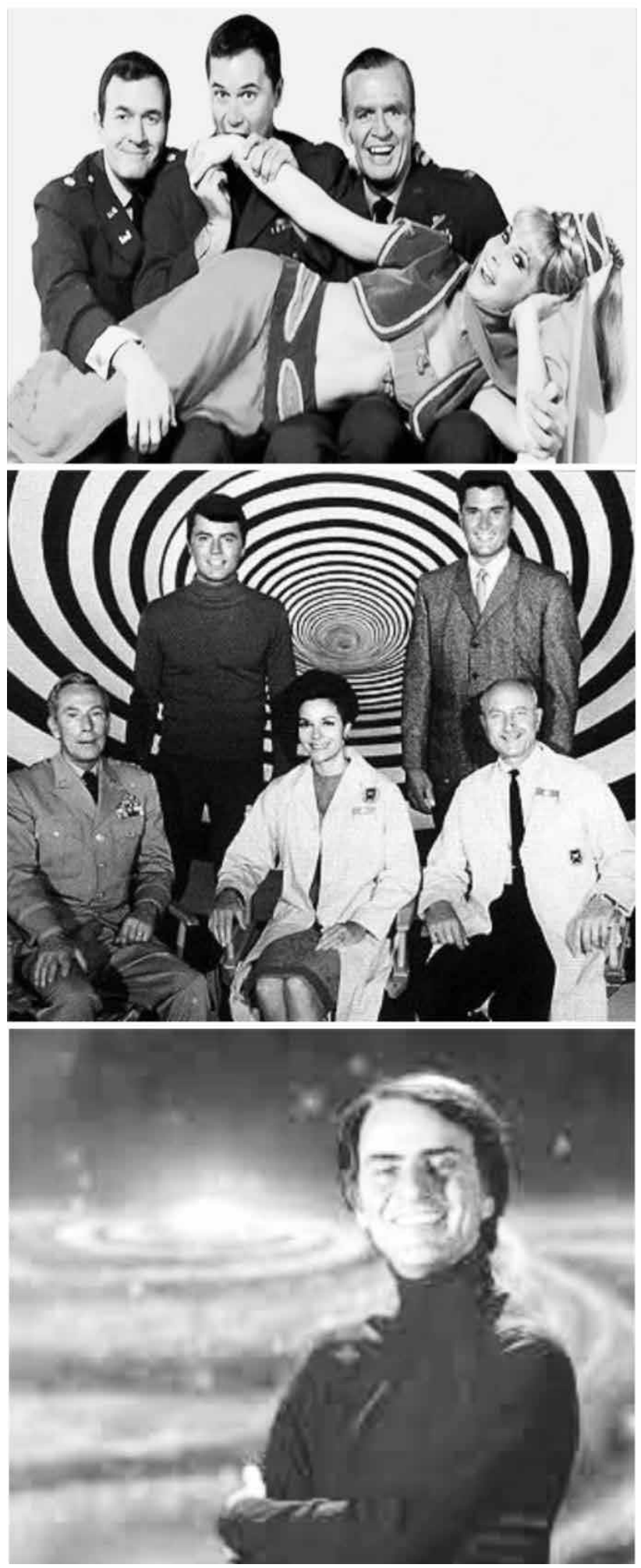


Tais tecnologias põem em funcionamento também uma nova visibilidade para o professor de ciências, que vem a reboque da figura do cientista. Não basta mais que as aulas comuniquem ou informem, elas precisam agora demonstrar e comprovar os fenômenos naturais. Cabe ao professor de ciências interpretar a natureza, ao manejar de forma hábil e eficiente, as metodologias que garantem o acesso à verdade. 0 profissional deve ser um misto de professor-cientista ou cientista-professor: duas formas que, de tão imbricadas e inter-relacionadas, não poderão ser separadas. Chaves (2010, p. 204) descreve como ela própria foi capturada por essa engrenagem e como isso se materializa na forma como olhamos o professor de ciências:

Aos sábados, em seu impecável blazer e camisa gola rolê, nosso professor de ciências era o astrofísico Carl Sagan, a desvendar diante de olhos atentos e maravilhados o fascinante e colorido mundo do Cosmos, estimulando nosso interesse pela ciência 0 modelo de professor era o cientista e o cientista era o que compreendia e dominava a natureza por meio de suas técnicas e método, o chamado método científico. Havia também o professor pardal a nos ensinar que ser bom cientista-professor (exatamente nessa ordem) exigia recolhimento, abnegação, renúncia e, sobretudo, muita, muita inteligência. Uma inteligência sobre humana, presente em poucos.

Se tais especificidades são requeridas aos professores, os cursos de formação de professores não podem ficar de fora, pois cabe a eles a responsabilidade de preparar um profissional que atenda as exigências do mercado. Um bom professor de ciências precisa ter domínio de saberes particulares, inseridos dentro de um conjunto de normas que passam a gerir a docência em áreas específicas do conhecimento, uma vez que a "educação científica se constituiu como um campo diferenciado de estudos, de investigações e de atuação profissional" (WORTMANN, 1999b, p. 3).

É nesse contexto que as aulas práticas e experimentais passam a ser propagandeadas como a solução para dar ao ensino das ciências ares mais modernos e dinâmicos, e é na década de 60 do século XX que elas se instalam de uma vez por todas nas escolas. Foi nessa década que o ensino de Ciências com atividades experimentais teve grande impulso a partir do desenvolvimento de projetos de ensino como, por exemplo, os oriundos dos EUA, que anunciavam o objetivo de "trazer formas mais estimulantes e eficazes às demonstrações e confirmações de fatos até então apresentadas apenas nos livros-texto ou por explanação do professor" (GALIAZZI et al, 2001, p. 253).

Esse tipo de ensino dizia despertar nos alunos o interesse pelas ciências e com isso incentivar a trajetória de uma carreira científica. Para isso, era necessário que os alunos aprendessem a observar e a registrar dados, pensar de forma científica, desenvolver habilidades e técnicas no manuseio do instrumental do laboratório: "acumular informações por meio da observação; organizar essas informações e procurar regularidades; perguntar por que elas aparecem e comunicar as descobertas aos outros" (GALIAZZI et al, 2001, p. 253).

A visão indutivista do método científico propagada nessa época ainda reverbera e sustenta os discursos sobre o ensino de Ciências de hoje, basta olhar, por exemplo, alguns projetos que pretendem lançar ares inovadores à educação básica pela inserção da pesquisa no cotidiano escolar. Tomemos como exemplo os editais dos projetos "Pará faz ciência na escola" e "PIBIC Jr".

O projeto "Pará faz ciência na escola" anuncia a intenção de contribuir para a me- 
lhoria do ensino básico através do financiamento de propostas que desenvolvam novas práticas pedagógicas, a serem "aplicadas no dia-a-dia da sala de aula". A chamada é direcionada a professores interessados em desenvolver pesquisas nas escolas públicas estaduais para (entre outros objetivos) "despertar a vocação científica e incentivar talentos entre os estudantes de ensino público do Pará" (EDITAL FAPESPA/SEDECT/SEDUC, 2010, p. 1). Dentre os critérios considerados para avaliação e consequente aprovação das propostas, vemos que terá preferência o projeto que estabelecer "parceria com pesquisadores de Instituições de Ensino de Pesquisa e/ou Ensino Superior" (EDITAL FAPESPA/SEDECT/ SEDUC, 2010, p. 1).

Outra chamada, desta vez para o financiamento de bolsas de iniciação científica para alunos da educação básica - o PIBIC Jr - funciona por meio de convênio entre o CNPq e as fundações estaduais de apoio à pesquisa. No segundo edital lançado pela FAPESPA, em 2009, a chamada é direcionada aos "pesquisadores de instituições de ensino e pesquisa ou pesquisadores de instituições de pesquisa sediadas no Estado do Pará" (EDITAL FAPESPA, 2009, p. 1). A concessão de bolsas de estudo para alunos da Educação Básica visa "despertar a vocação científica e incentivar talentos potenciais entre os estudantes, mediante participação em atividades científicas, orientados por pesquisadores e/ ou professores qualificados em instituições de ensino superior [...]" (EDITAL FAPESPA, 2009, p. 1).

A emergência dessa "nova" visibilidade para as aulas de ciências implica no aparecimento de novos conceitos, temas, objetos, imagens, que permitem ver e falar de forma diferenciada da que se via e dizia anteriormente, mas que ainda promete a possibilidade de inovação, modernização, dinamização das aulas de Ciências e Biologia, principalmente na educação básica.

Inovação e motivação são qualidades recorrentemente associadas pelos professores às aulas práticas de ciências, no entanto, Silva e Zanon (2000) discutem essa afirmação e defendem que entre professores não se tem clareza do papel da experimentação na aprendizagem dos alunos. Normalmente, as aulas práticas ou experimentais são consideradas importantes para que os alunos "vejam com seus próprios olhos" ou "vejam a realidade como ela é" o que acaba por reforçar a visão dogmática da ciência, segundo a qual o que é científico visivel e palpável (produzido e testado em laboratório), algo inquestionável, taxativo e exato. Com base nesses atributos, é possivel pensar a ciência como fato que está escondido por dentro dos fenômenos à espera de ser descoberto.

Se, para alguns, as aulas experimentais são requisitadas para garantir o efeito motivador, para outros tem efeito contrário. A menina do início de nosso texto cresceu e decidiu que seria professora de Biologia. Animada com o início de seu curso, esperou ansiosamente pelas tão famosas aulas práticas. Da escola de onde viera, os microscópios só existiam nos livros. No entanto, foi a essas aulas que ela creditou parte de seu desencanto com a Citologia, a primeira disciplina do curso. Depois de assistir com muita atenção todas as aulas teóricas de Biologia Celular chegara a vez de conferir o que havia aprendido. Ela estava ansiosa para ver a célula e suas estruturas. Achava que tudo isso iria se apresentar a ela no campo microscópico. Que emoção seria ver aquilo que só via pelos desenhos: uma célula de verdade, "ao vivo e em todas as suas cores"! Qual 
não foi sua frustração ao ver a célula pela primeira vez. Perguntou ao professor: "mas onde estão as organelas citoplasmáticas?" Queria ver em detalhes a rugosidade do retículo endoplasmático, as bolsas do complexo de Golgi, as cristas mitocondriais. No entanto, nada disso se apresentou diante de seus olhos. No lugar de mitocôndrias vermelhas e dos ribossomos em forma de oito colados na parede do retículo (como no livro) viu apenas algo que considerou tão "sem graça": uma coisa translúcida com uma "bolinha" um pouco mais escura no centro. "Aquilo" era a célula! Nem viva, nem em cores (Figura 4).

Figura 4 - Célula animal: o que a menina viu e o que ela achava que veria.

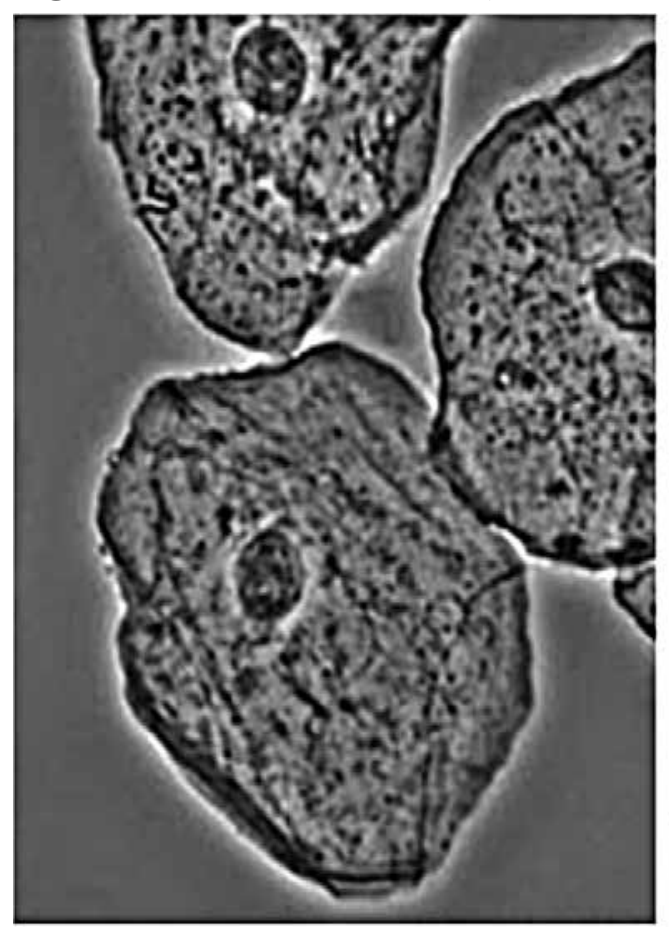

Nessa direção encaminharam-se também as aulas de Zoologia e Botânica, com animais mortos e plantas prensadas. Demorou um pouco para que entendesse que seu olhar deveria ser calibrado para uma forma que permitisse ver de modo diferente aquilo que estava acostumada a ver. Como futura bióloga (mas ela não queria ser professora de Biologia?), deveria ver a vida com outros olhos: olhos que the permitissem identificar, sob os mais diversos aparatos de visibilidade, uma vida dissecada, incolor, estática e morta! Tudo muito diferente do que aprendera a ver (e a gostar!), nos livros de Biologia.

Uma imagem que amplamente circula nas redes sociais nos move a pensar sobre como nós, professores de Biologia, devemos ver a vida que ensinamos na sala de aula. Nela, uma jovem lança um olhar para o alto, a mão no quei-

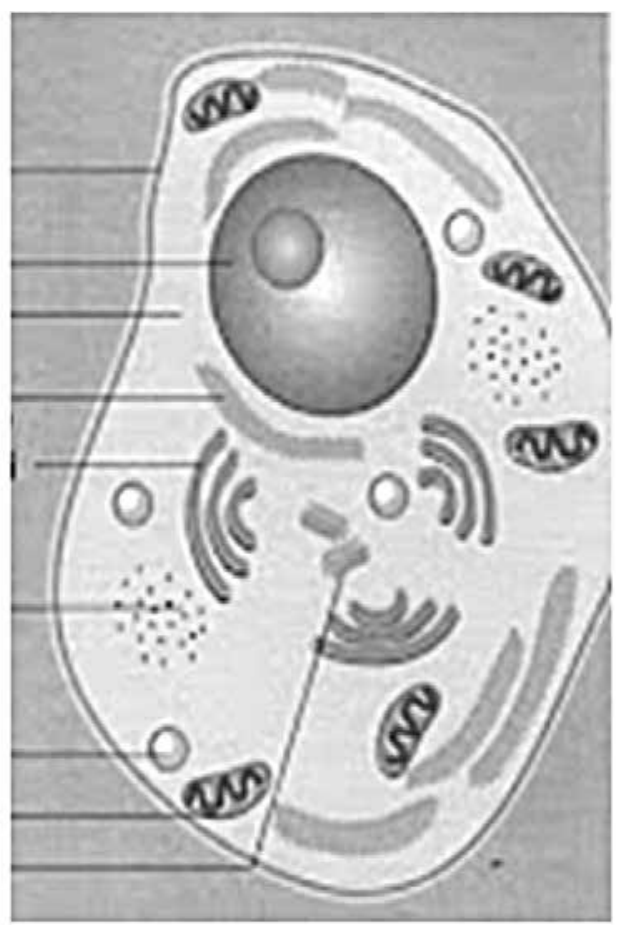

xo sugere que ela está pensando em algo. No primeiro quadro, intitulado "antes da Biologia", vemos alguns animais. Eles estão integrados ao ambiente em que vivem. A tartaruga, vista de frente, nada no mar. 0 peixe de um colorido intenso é visto à frente do que parecem ser os tentáculos de uma anêmona. 0 pássaro repousa sobre um galho e o lagarto assume uma posição atenta, como se espreitasse o ambiente e estivesse se preparando para a fuga. No quadro ao lado, "depois da Biologia", a mesma mulher ainda assume sua posição pensativa, mas o objeto de seu pensar tem agora outra configuração: os animais não mais aparecem em seus habitats. Não existe mais cor. Eles são mostrados em cortes anatômicos, como em um atlas, e nos detalhes observamos a denominação de suas estruturas internas e externas (Figura 5). 
Figura 5 - Olhar Biológico: postagem do Facebook.

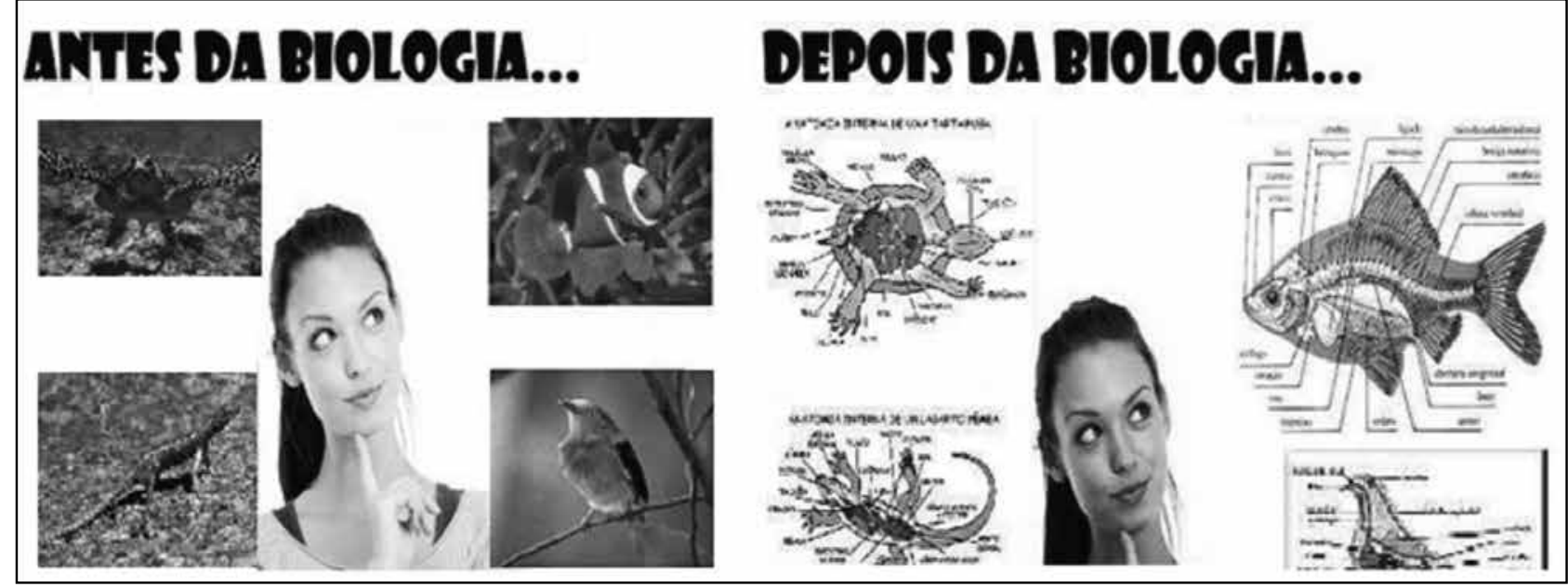

Essa imagem e seus detalhes remete automaticamente a outra, exposta na Feira do Vestibular em nossa Universidade. ${ }^{3} 0$ cartaz, intitulado "Olhar de Biólogo", traz vários elementos que nos direcionam a pensar que há realmente um olhar diferenciado desse profissional sobre a natureza. Animais em exposição, alguns em seu habitat natural, outros em laboratório, dissecados ou vivos, sendo manipulados ou não, remetem aos mesmos elementos da imagem anterior (Figura 6).

Figura 6 - Olhar de Biólogo: Cartaz da Feira do Vestibular.

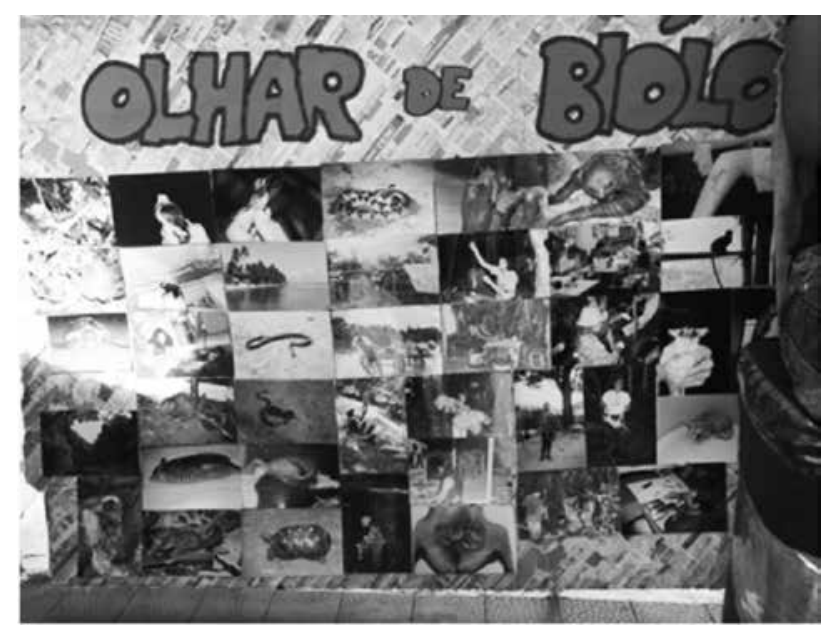

3 A Feira do Vestibular é um evento promovido pela Pró - Reitoria de Ensino de Graduação (PROEG-UFPA), para informar e orientar os estudantes do Ensino Médio sobre os cursos ofertados na UFPA e suas perspectivas de mercado de trabalho.
Situações e imagens como essas nos movem a perguntar: o que nos ensina a ver dessa forma? Em que momento passamos a enxergar a vida incolor e esquemática como a moça da figura? Existe mesmo um olhar biológico que nos permite ver as coisas de uma forma "diferente" do que é considerado "normal"?

A exigência e a necessidade dessa ortopedia do olhar parece sugerir um ordenamento nas coisas que se oferece como uma espécie de lei interior, uma rede secreta e silenciosa que espera o momento de ser enunciada. É como se o mundo fosse coberto por signos decifráveis, conhecíveis, identificáveis (FOUCAULT, 2007). Nesse contexto, o olho se torna depositário e fonte de clareza, tendo o poder de trazer à luz uma verdade que se encontra encoberta pelas brumas que ofuscam nossos olhos, nos impedindo de ver o contorno nítido das coisas (FOUCAULT, 2008). Para o professor de biologia, "portador dessa visão diferenciada" de ver o mundo, somente as aulas de biologia são capazes de dissipar essas brumas e salvar os alunos da cegueira.

Silva e Zanon (2000, p. 123) defendem que qualquer observação que fazemos pressupõe uma referenciação a memórias que registramos em nossas vivências e em nossas experiências. Não nascemos vendo desse ou daquele jeito, somos ensinados a ver. São vários 
os condicionantes que determinam aquilo que vamos enxergar, ou, nas palavras das autoras, "que nos fazem ver o que estamos a ver".

O visivel e o invisível não estão na dependência apenas de nossos olhos. Ver de um determinado jeito não depende do aguçamento do sentido da visão. Somos ensinados a ver de um determinado modo, já que o que se pensa (e o que se vê) é instituído pelo discurso, que longe de informar uma verdade a produz. E aquilo que se vê não é a verdade que emerge das coisas, mas o produto da exterioridade que cada um traz, a si e aos outros, do que se entende como mundo "real" (VEIGA-NETO, 2001). Sobre essa (in)visibilidade, François Jacob fala:

[...] mesmo quando um instrumento aumenta de repente o poder de resolução dos sentidos, ele representa apenas a aplicação prática de uma concepção abstrata. 0 microscópio é a reutilização das teorias físicas sobre a luz. E não basta 'ver' um corpo até então invisível para transformá-lo em objeto de análise. (JACOB, 1983, p. 21-22)

No universo microscópico da Citologia, inserido em outro campo de saberes e visibilidades que, até então, era novo para a menina, aquela imagem e seus códigos não faziam qualquer sentido. Ali, ela era simplesmente cega, pois ainda não havia aprendido a ver, e, portanto, ler o que se apresentava diante de seus olhos. Se em seu mundo "real" a célula a quem foi incontáveis vezes apresentada (e que a seduziu a estudar Biologia) era multicolorida e indissociável de todos os seus componentes, como ela poderia reconhecê-la de outra forma? Como poderia reconhecê-la sem a "maquiagem" que, no livro didático, a tornava mais bela aos seus olhos?

É o diverso cardápio de opções que nos é apresentado no mundo que emoldura nosso olhar para ver de uma determinada forma. Nossas práticas de significação processam-se permeadas pela cultura, que na acepção de Guimarães (2007), corresponde ao conjunto de práticas que imprimem significações sobre o mundo. Práticas históricas que marcam nossos corpos, como defende Foucault (1979), e forjam nosso olhar, a partir de uma série de regimes que o constroem. Dessa forma, o olhar não pode ser resumido a um simples ato fisiológico. Ver se encontra imbricado naquilo que aprendemos a distinguir como pertencente a um determinado conjunto "natural".

As aulas de Biologia com todos os seus aparatos de visibilidade são extremamente competentes em nos ensinar a ver e a naturalizar determinado mundo. Elas corrigem nosso olhar, para nos fazer enxergar o mundo tal qual a moça da ilustração citada anteriormente. No caminho que é traçado para os que pretendem ser biólogos, esse olhar não só é necessário como também cobrado. Não à toa que o cartaz que pretende homenagear o biólogo no seu dia, traz como enunciados justamente equipamentos que são reiteradamente atribuídos ao seu fazer laboral (microscópio e binóculo). Equipamentos estes que permitem o aparelhamento da visão para ver mais e meIhor! Que garantem uma visão "além do alcance!" - sugerindo que só o biólogo é capaz de ver coisas que ninguém mais vê! (Figura 7).

Figura 7 - Cartaz alusivo ao dia do Biólogo.

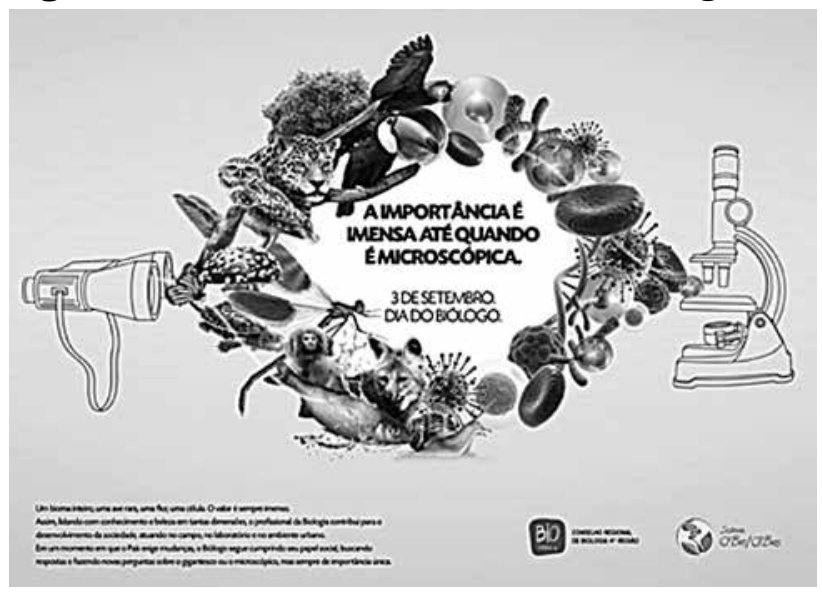

O texto, alinhado no canto inferior esquerdo da figura, remete às diferentes es- 
calas de tamanho que a vida assume: “Um bioma inteiro, uma ave rara, uma flor, uma célula. O valor é sempre imenso. Assim, lidando com conhecimento e beleza em tantas dimensões, o profissional da Biologia contribui para o desenvolvimento da sociedade, atuando no campo, no laboratório e no ambiente urbano. Em um momento em que o país exige mudanças, o Biólogo segue cumprindo seu papel social, buscando respostas e fazendo novas perguntas sobre o gigantesco e o microscópico, mas sempre de importância única". ${ }^{4}$

Ao falar sobre a importância desse profissional na sociedade, o texto faz alusão às diversas formas de vida nas suas mais variadas dimensões desde um "bioma inteiro", passando por "uma ave rara, uma flor" até chegar à diminuta célula. Todo esse espectro de visibilidade, do micro ao macro, tem objetos que não escapam à curiosidade desse profissional. Para cumprir com a missão de contribuir com seu trabalho para o desenvolvimento da sociedade, o biólogo pode atuar no "campo, no laboratório e no ambiente urbano". Nunca na escola!

A constante evocação de espaços privilegiados para garantir uma formação não apenas mais eficiente como diferenciada para o Biólogo, remete à preocupação que se tem de mostrar formas privilegiadas para ver o mundo, supostamente, tal como ele é. O mundo natural!

\section{Desejos}

Pois bem, sonho com uma ciência - digo mesmo uma ciência - que teria por objeto esses espaços diferentes, esses outros lugares, essas contestações míticas e reais do espaço em que vivemos. Essa ciência estudaria não as utopias, pois é preciso reservar esse nome para o que verdadeiramente não tem lugar algum, mas as hetero-topias, espaços absolutamente outros;

4 Grifos nossos. e, forçosamente, a ciência em questão de chamaria, se chamará, já se chama 'heterotopologia'. (FOUCAULT, 2013, p. 20-21)

Nessa seara podemos afirmar como Mia Couto (2011, p. 49) que "somos herdeiros de uma ideia de ciência que vive de costas para a necessidade de trazer leveza e construir beleza", pois "aquilo que se pretende científico deve-se apresentar de trajes cinzentos e solenes, de forma estática, sem poesia". Nossas aulas de Biologia assim caminham, quando insistimos em mostrar e recitar uma "vida" completamente distante daquela que se vive fora da escola.

Em nossa trajetória como professoras formadoras de outros professores de Ciências e Biologia, pensamos que é preciso abandonar certos costumes que, de tão acionados, nos aprisionam e engessam em práticas pedagógicas sem sentido, sem cor e sem sabor. Práticas que não causam espanto, curiosidade, alegria... Que confinam nossas aulas a espaços mórbidos com seres dissecados ou fixados em álcool e formol.

Inspiradas pelas palavras do biólogo poeta (ou poeta biólogo?), pensamos ser preciso nos rebelar contra um currículo que tem a intenção de "decepar nossas raízes mais profundas, obrigando-nos à cerimônia de palavras mortas" (COUTO, 2009, p. 51). Para uma docência que pretende ensinar e estudar a vida é preciso fugir das certezas e engessamentos dos manuais didáticos. É preciso ter coragem para reinventar processos, povoar-nos de ternura, de gente, de poesia, de vida!

Olhar de frente a verdade das pequenas coisas: esta água vem de onde? Quem teceu seu linho? Que mãos fizeram esse pão? Deslocar-nos para tudo ver de outro lado, de outro modo, ver de outra forma (e fora da fôrma) aquilo que é constantemente visto: trazer ao olhar, o desejo de um princípio infinitamente retomado. Ganhar sonoridade nas vozes que 
nos habitam silenciosamente. Entre mar e terra, preferir ser espuma, ter raiz e poente entre oceano e continente (COUTO, 2009).

É preciso desaprender o aprendido para poder ser partícipe da força de transformação, transfiguração, procriação e criação de uma educação que se pretende nova, viva, interessante, colorida. Pois ser professor, não é só acumular, guardar conservar, usar. É também

\section{Referências}

CHASSOT, Áttico. Ensino de ciências no começo da segunda metade do século da tecnologia. In: LOPES, Alice Casimiro; MACEDO, Elizabeth. (Orgs.). Currículo de ciências em debate. São Paulo: Papirus, 2004. p. 13-44.

CHAVES, Sílvia Nogueira. Receita de bom professor: todo mundo tem a sua, eu também tenho a minha! In: CUNHA, Ana Maria de Oliveira et al. (Orgs.). Convergências e tensões no campo da formação e do trabalho docente. (Textos selecionados do XV ENDIPE). Belo Horizonte: Autêntica. 2010. p. 200-216.

CORAZZA, Sandra. 0 que quer um currículo? Pesquisas pós-críticas em Educação. Petrópolis, RJ: Vozes, 2001.

COSTA, Marisa Vorraber. Currículo e política cultural. In: COSTA, Marisa Vorraber. 0 currículo nos limiares do contemporâneo. 4. ed. Rio de Janeiro: DP\&A, 2005. p. 37-68.

COUTO, Mia. E se Obama fosse africano? E outras interinvenções. São Paulo: Companhia das Letras, 2011.

COUTO, Mia. Raiz de orvalho e outros poemas. 4. ed. Moçambique. Editora Caminho, 2009. (Coleção Outras Margens, 82).

Edital FAPESPA/SEDECT/SEDUC no 013/2010 - Programa Pará faz Ciência na Escola - PPCE.

Edital FAPESPA no 007/2009 - Programa de Bolsas de Iniciação Científica Júnior - PIBICJR.

FOUCAULT, Michel. A microfísica do poder. Tradução abandonar, deixar para trás velhos hábitos e esquemas, planos empoeirados, jalecos gastos. Trata-se assim de possuirmos instrumentos para sermos felizes. E o segredo é estar disponivel para que outras (bio)lógicas nos habitem, é visitarmos e sermos visitados por outras sensibilidades (COUTO, 2011). Quem sabe assim, um dia, a biologia possa ser também poesia e voltar a ter vida.

de Roberto Machado. Rio de Janeiro: Edições Graal, 1979.

FOUCAULT, Michel. A ordem do discurso. Tradução de Laura Fraga de Almeida Sampaio. Rio de Janeiro: Edições Loyola, 2009.

FOUCAULT, Michel. A vida dos homens infames. In: MOTTA, Manoel Barros. Estratégia, poder-saber. 2. ed. Rio de Janeiro: Forense Universitária, 2008. p. 201-222. (Coleção Ditos \& Escritos, IV).

FOUCAULT, Michel. As palavras e as coisas: uma arqueologia das Ciências Humanas. Tradução Salma Tannus Muchail. 9. ed. São Paulo: Martins Fontes, 2007.

FOUCAULT, Michel. 0 corpo utópico, as heterotopias. Tradução de Salma Tannus Muchail Year. São Paulo: n-1 Edições, 2013.

GALIAZZI, M. C.; GONÇALVES, F. P.; ROCHA, J. M. B.; SCHMITZ, L. C.; GIESTA, S.; SOUZA, M. G. Objetivos das atividades experimentais no ensino médio: a pesquisa coletiva como modo de formação de professores de ciências. Ciência \& Educação, v. 7, n. 2, p. 249-263, ago. 2001.

GOODSON, Ivor F. História do currículo, profissionalização e organização social do conhecimento: paradigma para a história da Educação. In: GOODSON, Ivor F. Currículo: teoria e história. Tradução de Attílio Brunetta. 9. ed. Petrópolis, RJ: Vozes, 2010. p. 115-141.

GUIMARÃES, Leandro Belinaso. Pesquisas em educação ambiental: olhares atentos à cultura. In: WORT- 
MANN, Maria Lúcia Castagna; SANTOS, Luís Henrique Sacchi; RIPOLL, Daniela; SOUZA, Nádia Geisa Silveira; KINDEL, Eunice Aita Isaia. (Orgs.). Ensaios em estudos culturais, educação e ciência; a produção cultural do corpo, da natureza, da ciência e da tecnologia: instâncias e práticas contemporâneas. Porto Alegre: Editora da UFRGS, 2007. p. 237-245.

JACOB, François. A lógica da vida: uma história da hereditariedade. Rio de Janeiro: Edições Graal, 1983.

PARAÍSO, Marlucy Alves. Currículo, desejo e experiência. Educação \& Realidade, v. 34, n. 2, p. 277-293, mai./ago. 2009.

POPKEWITZ, Thomas. História do currículo, regulação social e poder. In: SILVA, Tomaz Tadeu. (Org.). 0 sujeito da educação: estudos foucaultianos. 7. ed. Petrópolis, RJ: Vozes, 2010. p. 173-210.

SILVA, Lenice Heloísa de Arruda; ZANON, Lenir Bassalo. A experimentação no ensino de ciências. In: SCHNETZLER, Roseli Pacheco; ARAGÃO, Rosália M. R. (Orgs.). Ensino de ciências: fundamentos e abordagens. Campinas, SP: R. Vieira Gráfica e Editora Ltda., 2000. p. $120-153$.

SILVA, Tomaz Tadeu. Documentos de identidade: uma introdução às teorias do currículo. 3. ed. Belo Horizonte: Autêntica, 2010.

TELLES, Lygia Fagundes. Invenção e memória. São
Paulo: Companhia das Letras, 2009.

VEIGA-NETO, Alfredo. Currículo e história: uma conexão radical. In: COSTA, Marisa Vorraber. (Org.). 0 currículo nos limiares do contemporâneo. 3. ed. Rio de Janeiro: DP\&A, 2001. p. 93-104.

WORTMANN, Maria Lúcia Castagna. A educação científica e os estudos culturais. In: FÓRUM SUL DOS COORDENADORES DE PÓS-GRADUAÇÃO-ANPED, II, 1999, Curitiba. Programação Geral do II Fórum Sul da ANPEd, Curitiba, v. 1, p. 1-4. 1999b. Disponível em: <http://www.portalanpedsul.com.br/admin/ uploads/1999/Educacao em Ciencias Naturais e matematica/trabalho/12 1407 a educacao cientifica e os estudos culturais.pdf>. Acesso em: 24 nov. 2012.

WORTMANN, Maria Lúcia Castagna. Currículo e ciências: as especificidades pedagógicas do ensino de ciências. In: COSTA, Marisa Vorraber. (Org.). 0 currículo nos limites do contemporâneo. 4. ed. Rio de Janeiro: DP\&A, 2005. p. 129-157.

WORTMANN, Maria Lúcia. Localizando o ensino das ciências na instrução escolar do Rio Grande do Sul. Episteme, Porto Alegre, n. 9, p. 81-99, jul./dez. 1999a.

Recebido em: 28.08.2017

Aprovado em: 05.11.2017

Sandra Nazaré Dias Bastos é Doutora em Educação em Ciências e Matemáticas pela Universidade Federal do Pará. Professora Adjunta IV do Instituto de Estudos Costeiros/Campus de Bragança. Grupo de Estudos e Pesquisa em Educação Científica e Ambiental (GEPECA).e-mail: sndbastos@gmail.com

Alameda Leandro Ribeiro, s/non, Aldeia, Bragança, Pará, CEP: 68600-000. Telefone: (91) 981796426

Sílvia Nogueira Chaves é Doutora em Educação pela UNICAMP. Professora Associada IV do Instituto de Educação Matemática e Científica. Grupo de Pesquisa em Cultura e Subjetividade (GEPECS). e-mail: schaves@ufpa.br

Rua Augusto Corrêa, no 1, Guamá, Belém, Pará, CEP: 66075-010. Telefone: (91) 988436326 